\title{
Heart-shaped intracranial aneurysm
}

\author{
Aneurisma intracraniano em forma de coração \\ Zheng Feng', Guibo Lin², Ke Meng', Weidong Yư ${ }^{3}$, Chao Fu ${ }^{3}$
}

A 45-year-old woman presented with severe headache for three hours. Non-contrast brain CT revealed subarachnoid hemorrhage, mostly in the prepontine cistern (Figure A). A catheter-based angiogram showed a heart-shaped aneurysm arising from the junction of the basilar artery and the left superior cerebellar artery (Figures B and C), which was then coiled uneventfully (Figure D).
Cerebral aneurysm with a heart-shaped configuration is interesting and extremely rare, which is usually associated with vessel-wall degeneration under hemodynamic stress ${ }^{1}$. Surgical clipping is challenging because of the complex anatomic environment and fragile aneurysmal wall; while an endovascular procedure, as a straightforward option, seems to be feasible and effective $e^{2,3}$.
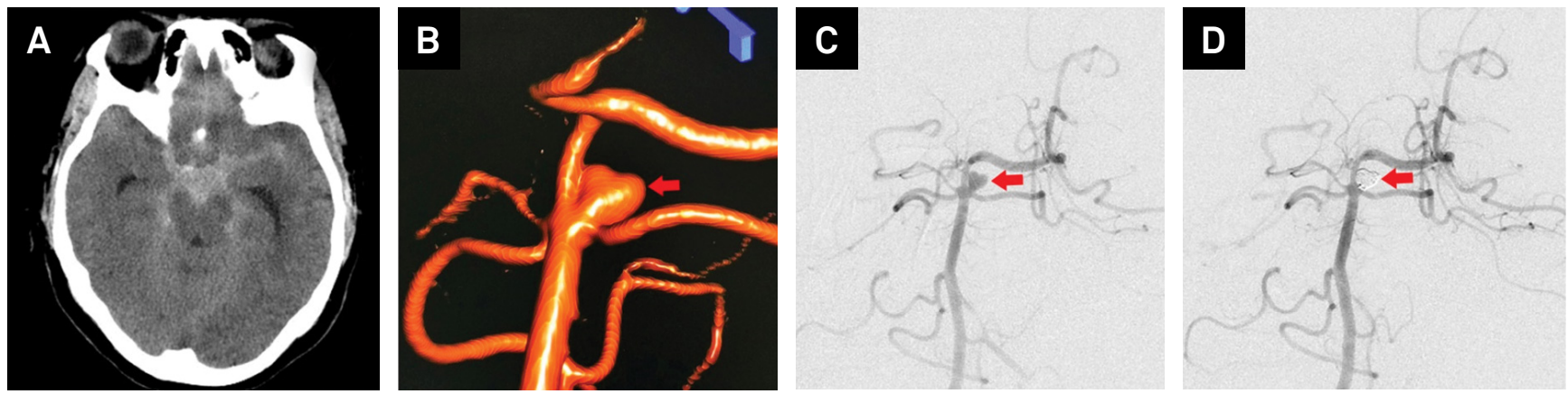

Figure. (A) Non-contrast head CT shows subarachnoid hemorrhage in the prepontine cistern. (B-C) Catheter-based angiogram shows a heart-shaped saccular aneurysm (arrows) originating from the bifurcation of the basilar artery and the left superior cerebellar artery. (D) Postoperative angiogram shows the aneurysm (arrow) coiled successfully.

\section{References}

1. Vajkoczy P, Hartmann M. An unusual saccular aneurysm. N Engl J Med. 2002 Feb;346(7):497. https://doi.org/10.1056/NEJMicm010008

2. Fu C, Zhao C, Zhao H, Li D, Yu W. Growing dissecting aneurysm of basilar trunk treated with stent-assisted coiling. J Stroke
Cerebrovasc Dis. 2015 Jan;24(1):e5-9.

https://doi.org/10.1016/j.jstrokecerebrovasdis.2014.07.033

3. Gong D, Yan B, Dowling R, Mitchell P. Successful treatment of growing basilar artery dissecting aneurysm by Pipeline flow diversion embolization device. J Stroke Cerebrovasc Dis. 2014 Jul;23(6):1713-6. https://doi.org/10.1016/j.jstrokecerebrovasdis.2013.11.019

\footnotetext{
${ }^{1}$ China-Japan Union Hospital of Jilin University, Department of Pediatrics, Changchun, China; ${ }^{2}$ China-Japan Union Hospital of Jilin University, Department of Rehabilitation, Changchun, China; ${ }^{3}$ China-Japan Union Hospital of Jilin University, Department of Neurosurgery, Changchun, China. Chao Fu (iD) https://orcid.org/0000-0003-1022-4350
}

Correspondence: Chao Fu; Department of Neurosurgery, China-Japan Union Hospital of Jilin University, No. 126 Xiantai Street, Changchun 130033, Jilin Province, China; E-mail:fc616@126.com 